\title{
Semblanza de Mario Alzamora Valdez
}

\section{Carlos Fernández Sessarego}

\section{De Cajamarca a Lima}

E N LA SEGUNDA década del siglo en que vivimos, en un día que E nos resulta impreciso, Mario Alzamora Valdez llega a Lima desde su lejana Cajamarca. Ha dejado atrás una infancia que discurrió serena, ambientada en una bella campiña, marco propicio para la meditación y el ensueño. No fue mucho, probablemente, lo que ofreció culturalmente, por aquel entonces, su terruno natal. Empero, ello no sería óbstáculo para la acertada formación y el equilibrado desarrollo intelectual del futuro profesor de filosofia. Su inquietud y su talento natural, del que nos ha dado abundante testimonio en su vida ejemplar, lo impulsaron a buscar nuevos y más amplios horizontes. Su meta seria la Universidad Nacional Mayor de San Marcos, cuya tradición y bien ganado prestigio to entusiasmaron como a tantos otros jóvenes de aquella época. Iniciariase asi una vida entregada generosamente a esta Casa, un senero magisterio que no conocería pausas ni flaquezas, una constante siembra de fecundas ideas.

No fue fácil, sin duda, la adaptación de Alzamora Valdez al ritmo y a las costumbres de la ciudad capital, que disfrutaba los despreocupados anos de la "belle époque". de la bohemia del Palais Concert y la Exposición, de los fastuosos carnavales y los reinados de belleza, de los furtivos encuentros en el Paseo Colón, que desmarcaba el confin de la ciudad. Eran los tiempos del gobierno de don Augusto B. Leguía.

- Discurso de orden pronenciado en el homenaje tributado por la Universidad Nacional Mayor de San Marcos el 7 de Mayo de 1994 
El ingreso a la Universidad se alzaba como un reto para el alto y enjuto estudiante, de andar pausado y expresión vivaz, El examen de admisión significó un difícil enfrentamiento con un exjgente jurado compuesto de cinco miembros, presidido por Ernesto de la Jara y Ureta. La severa sala de lectura de la recordada Biblioteca Central de la Casona servia de escenario, casi inquisitorial, a una dura y prolongada prueba oral rendida ante profesores formales y distantes, en la que el postulante debía no sólo demostrar su saber e inteligencia sino su presencia de ánimo y personalidad. Mario Alzamora Vaidez salió airoso de aquel trance y obtuvo el más alto calificativo en dicha ocasion.

No podía estar rodeado de los mejores auspicios el ingreso de Alzamora Valdez a la Universidad que hoy, merecidamente, lo honra y distingue, Su tránsito por las vetustas aulas sanmarquinas convalidaria la proeza juvenil. Los acogedores y amenos claustros de nuestra Casa, que evocamos con nostalgia, serian silentes testigos del transcurrir de un triunfador, de un estudiante de indiscutible talento, de mentalidad profunda y ordenada, capaz de ahondar con lucidez y coherencia los temas măs complejos de nuestra trascendente existencia.

\section{La Universidad}

No atravesaba San Marcos por su mejor momento cuando Alzamora Valdez hace su ingreso a la Universidad. Contrastaria con la quietud de la apacible provincia el tumultuoso ambiente estudiantil y el agitado debate sobre la problemática nacional que se desarrollaba en el claustro, en el que era notorio una casi general limitación de perspectivas y de lideres de suficiente estatura intelectual. No era infrecuente que la confrontación de ideas se resolviese mediante la contundencia argumental del silletazo, precursor del palo y la piedra de estos convulsos tiempos.

El sistema imperante no era el más propicio para el adecuado desarollo de una promoción de jóvenes plenos de energía creadora, cargada de ilusiones y proyectos sobre el pais y la Universidad. Por el contrario, el clima político tendía a ahogar tan nobles y generosos propósitos y más bien, al arrinconar dichos impulsos originaba el insurgir de una generación expectante y tímida en una Universidad en la que sólo se programaba la formación de profesionales, hombres de licencia y diploma. En esta circunstancis el asombro de Mario Alzamora Valdez no podia devenir en deslumbre. 
La oscura etapa comenzaria pronto a despejarse A ello contribuyó el acceso al Rectorado de San Marcos del eminente educador don José Antonio Encinas, Los que lo conocieron personalmente y fueron sus discipulos recuerdan el positivo aporte del maestro Encinas a la recuperación de la Universidad. Con vocación de maestro, Encinas proyecta su personalidad en la vida institucional e imprime carácter a la actividad universitaria. Recoge y siembra inquietudes, abre el diálogo en todas las direcciones, promueve el acercamiento entre autoridades y estudiantes, no sólo a través de una política de puertas abiertas sino mediante una permanente aproximación a los discentes, incluso en los propios claustros de la Universidad. En este nuevo ambiente, proclive a la realización del llamado interior, Alzamora Valdez, encuentra los estímulos exteriores necesarios para desarrollar armoniosamente su vigorosa personalidad, decidir su personal e intransferible periplo intelectual, su propio proyecto vital.

El maestro Alzamora Valdez recuerda complacido el resurgir de San Marcos bajo la hábil conducción de Encinas. Rememora, con legitima satisfacción, el salto de calidad producido en aquel instante de la historia de nuestra antigua Universidad. No puede olvidar que el reverdecer de la vida universitaria se debió, en gran medida, a la apertura que se operó en San Marcos, la que permitió el ingreso a la docencia de una nueva y valiosa promoción de maestros que dejaron perdurable huella. Porras Barrenechea, Abastos, Chiriboga, entre otros, son los nombres que dan lustre a nuestra Vieja Casa, que contribuyen al resplandecer de la actividad universitaria cuyos ingredientes son la devoción por la investigación, la honestidad intelectual y la generosa entrega a la docencia con desasimiento de los bienes materiales que otros oficios brindan de modo elocuente.

La enseñanza de maestros como los anteriormente nombrados signaron el futuro de Alzamora Valdez, se constituyeron en paradigmas que contribuirian a afirmar su vocación intelectual y su pasión por la ensenanza. Los que tuvimos el privilegio de ser discípulos de Raúl Porras en el apogeo de su impar magisterio, no sabemos si admirar más en su obra la pulcritud y elegancia de la forma o la profundidad de las ideas, la exactitud del dato verificado en la propia fuente o la probidad intelectual te la que dio abundante prueba. Porras surge en la memoria de Alzamora Valdez como el maestro dedicado a tiempo completo a la Universidad. en perenne actitud de cordial acogida y comprensión hacia los jóvenes. exigiéndoles acercarse a las fuentes, impulsándolos a la lectura de los clásicos, orientándolos en la investigación, enseñandoles a gustar el deleite 
de la busqueda y del hallazgo de la verdad cientifica, mostrándoles cuản necesaria es la imaginación en los prolegómenos de toda aventura intelectual.

Mientras que en aquel momento en la Facultad de Letras Porras profesaba literatura castellana y Abastos enseñaba historia moderna, Chiriboga era docente de filosofia. Alzamora Valdez encuentra en Chiriboga al maestro que influiría en la definición de su raigal vocación filosófica y que la apoyaria en sus primeras andanzas como investigador.

\section{El Colegio Universitario}

En los umbrales de la década del treinta, bajo el fugaz pero fruetifero rectorado de Encinas, hallamos a Alzamora Valdez, aún estudiante, como distinguido y elogiado profesor del Colegio Universitario, al lado de otros jóvenes de talento, alentados por el Rector de San Marcos. El Colegio Universitario se constituiria en centro de formación de profesores universitarios, lugar indicado para la definición de vocaciones y para el dialogo e intercambio de experiencias con profesores consagrados que incitaban constantemente a la investigación y la docencia. En el Colegio Universitario se inicia el ininterrumpido y singular magisterio de Alzamora Valdez,

\section{Los estudios de Derecho}

El tránsito de la Facultad de Letras a la de Derecho resultaba a menudo decepcionante para cierto sector de la juventud encandilada por la brillantez de los estudios de humanidades. Quedaba atrás un ambiente favorable para la creatividad intelectual y era sustituido por otro donde, con honrosas excepciones, se impartía una anacrónica ensefanza. Ello explicuria, tal vez, algunas deserciones de jóvenes valiosos que no encontraron aliciente para mantener una no muy robusta vocación por los estudios juridicos.

En el imicio de los anos treinta cundía cierta desorientación en la Facultad de Derecho. Los profesores, no siempre diligentes, repetian con frecuencia formulas no tamizadas por la crítica, asfixiados probablementi por el agobio del temor reverencial. Se ensenaba, en la mayoría de los casos, autores en trance de ser superados, como Colin y Capitant. 
o se introducía otros, como el caso de Icilio Vanni, cuyo pensamiento no gravitó en su propia patría. En este a menudo árido y desalentador ambiente emergian algunas figuras ilustres, dignas de mención, como las de Alberto Ulloa Sotomayor a Angel Gustavo Cornejo, entre otros. Ulloa renovó la ensenanza del Derecho Internacional Público y congregó a su alrededor a un numeroso y destacado grupo de jóvenes que se formaron bajo su acertada đirección. Angel Gustavo Cornejo, por su parte, nos legó una significativa producción juridica, constituyéndose en un animador de excepción de la tarea intelectual no sólo en los claustros universitarios sino también en reuniones tenidas en su propia casa,

\section{La Universidad Católica}

Alzamora Valdez no pudo concluir sus estudios de Derecho en San Marcos, ya que el General Sánchez Cerro cerró la Universidad, Un nutrido grupo de jóvenes tuvo que emigrar a la Universidad Católica. En este centro de estudios Alzamora Valdez trataría de cerca al Rector, Padre Jorge Dintilhac, quien lo orientaria hacia la lectura y reflexión de autores neotomistas como Maritain, Gilson, Tonquedec, Garrigou Lagrange. La reflexión y profundización del pensamiento tomista serían decisivos en la formación del maestro y le servirfan de permanente sustento en su futura carrera de investigador y docente.

De 1934 a 1961 Alzamora Valdez ejerció la docencia en la Universidad Católica. Tuvo a su cargo las cátedras de Metafísica, Psicología General, Lógica y Etica. Los numerosos alumnos que frecuentaron sus lecciones recuerdan la profundidad y precisión de sus clases, la seriedad de su magisterio, su vasta crudición. Sus libros de Metafísica y Psicología, inspirados por el pensarniento tomista, recogen su logracio esfuerzo en la docencia de estas disciplinas.

\section{San Marcos y la renovación del Derecho Procesal Civil}

Después de algunos afios dée docencia en la Universidad Católica, Alzamora Valdez es solicitado por su Alma Mater para ensenar ciiversos cursos en la antigua Facultad ue Derecho. En 1948 asume las cátedras de Derecho Procesal Civil e Introducción al Derecho, La presencia del ilustre maestro en el claustro sanmarquino concita la admiración de sus discípulos que aprecian en Alzamora Valdez su solida estructura intelec- 
tual, la limpida coherencia de sus disertaciones, un rigor y una eruitición poco comunes, su calidad moral.

Alzamora Valdez será recordado siempre como el maestro que renovó la enseñanza del Derecho Procesal Civil en el país, otorgándole dignidad cientifica. Con el maestro sanmarquino se inicia una nueva etapa en la docencia de dicha asignatura y se produce el tránsito de una enseñanza rutinarin, que se satisfacia con la simple exégesis de los textos legales, a otra diferente en la cual se exponía la estructura de la teoría procesal. Con Alzamora se advierte la sustitución del llamado "procedimentalismo" por el "procesalismo", se marca el paso de una actitud que se costrifie al fiel sometimiento a la ley a otra que supone la exposición de una concepción cientifica del Derecho Procesal. Alzamora Valdez introduce en el Perú los novedosos planteamientos de las escuelas alemana, italiana y argentina, dejando atrás la estrecha visión del Derecho Procesal Civil como un menester práctico para mostrarlo en su verdadera dimensión cientifica. El maestro sustenta sus tesis en el pensamiento de ilustres juristas como Chiovenda, Carnelutti y Alsina.

Por vez primera en nuestro medio académico, Alzamora Valdez asume el tratamiento teórico de las tres grandes instituciones del Derecho Procesal Civil, o sea, el proceso, la acción y la jurisdicción. En concordancia con Chiovenda considera que el proceso es una institución autónoma, unitaria y de carácter zúblico, mientras que la acción es caracterizada como un derecho autónomo, subjetivo, público, "que corresponde a toda persona de acudir ante el órgano jurisdiccional del Estado en demanda de amparo de una pretensión". La jurisdieción, segủn la enseñanza de Carnelutti, es el deber-poder del Estado de amparar toda acción. ${ }^{1}$

Alzamora Valdez, superanco anacrónicas enseñanzas, elimina del léxico procesal los imprecisos términos de "juicio" y "pleito", sustituyénđolos por la expresión "proceso". Esta innovación terminologica trasunta, sin embargo, una teoria procesal en la que se descarta el rol tradicional del juez como un simple mecánico aplicador de la ley, para presentarlo, en cambio, como el centro de la relación procesal, como un elemento creador cuya misión esencial es la de impartir justicia Esta propuesta conlleva el otorgar al jucz, en cuanto representante del Estado, una mayor y más activa participación en el proceso para lograr. mediante el empleo


1936-1976", Rer, de Derecho y Clencias Políticas, Vol, 40, No 1.2 y 3 ene dic 1976, Limz. pág. 194, 
de métodos apropiados. "la realización de una justicia más acertada y pronta". Se trata, en fin, de dinamizar el proceso en orden al bien común. superando la falta de iniciativa probatoria del juzgador.

Decidido critico del vetusto Código de Procedimientos Civiles de 1912. cuyo modelo es la Ley de Enjuiciamiento Civil española de 1881. Alzamora se muestra contrario al exagerado privatismo del Código de 1912 que "deja el proceso a disposición de las partes con menoscabo de la función del juez, lo que significa un permanente peligro para la justicia" 2 . Como corolario de los nuevos y científicos planteamientos del Derecho Procesal Civil, el maestro sanmarquino es partidario de la renovación total del Código de 1912, discrepanto tajantemente de quienes estiman que es suficiente realizar simples cambios parciales. Su firme actitud contrasta con la de aquellos a quienes satisface la sola modificación de ciertos aspectos del articulado del Código vigente ya que, como profundo y calificado estudioso de la materia, es consciente de la imperiosa necesidad de implantar, a nivel normativo, una nueva teoría procesal, para lo cual es insuficiente la dación de una o varias leyes de enmiendas del articulado del Código.

Al conmemorarse en 1962 el cincuentenario de la promulgación del Código de Procedimientos Civiles de 1912, Alzamora Valdez sosticne la posición radical de revisar y restructurar integramente dicho Código. Este planteamiento es propuesto en el seno de la Comisión creada para el estudio del Código de 1912, acordíndose en 1963 aceptar la iniciativa de Alzamora Valdez conciucente a la redacción de un nuevo cuerpo de leyes. Lamentablemente, pese a la tenaz acción del maestro, no se ha logrado hasta la fecha contar con un nuevo Código que sustituya totalmente al de 1912.

Por el contrario, de 1963 a la fecha se han producido diversas modificaciones parciales, las que no sólo no han resuelto la problemática expuesta sino que han complicado notoriamente la aplicación de las normas procesales vigentes. La rutina, la inacción, la pereza y falta de iniciativa, el espiritu retardatario o conservador de muchos y la tesinformación de algunos otros han impedido que las ideas de Alzamora Valdez. acordes con la más autorizada y reciente doctrina, se plasmen en un nuevo Código de Procedimientos Civiles. Esperemos que dichas fuerzas negativas no perseveren tratánciose de la renovación del Código Civil de 1936 que, 
al igual que el de Procedimientos Civiles, requiere superar de modo organico una ideologia acentuadamene individualista, marcadamente liberal y patrimonialista por otra de inspiración humanista y de contenido social. Como es obvio, este fundamental requerimiento, por su propia envergadura y más allá de las exigencias originadas por las transformaciones operadas en la sociedad y el desarrollo de la ciencia, obliga a una restructuración total del Código Civil de 1936, sin que ello signifique desestimar aquellas instituciones o reglas que, por haber demostrado su bondad a través del tiempo, mantienen su vigencia. Mediante cambios parciales, leyes de enmiendas o simples modificaciones resulta imposible, de manera racional y técnica, reemplazar una ideologia caduca por otra acorde con la época.

Como resultado de sus investigaciones, de su constante preocupación por renovar la ciencia procesal en el país y como opimo fruto de su extraordinaria labor académica, Alzamora Valdez publica en 1953 su valioso y difundido libro "Derecho Procesal Civil, Teoria General del Proceso", el mismo que por su calidad ha alcanzado nueve ediciones a la fecha. El eitado libro, de imprescindible lectura para quienes deseen obtener una adecuada y actual información sobre la materia, le valió a Alzamora Valdez la obtención en 1960 del Premio de Fomento a la Cultura. La obra de Alzamora trasciende los límites de la cátedra para cubrir, a partir de nuestra Universidad, toda una fructiffera etapa en el desarrollo de la ciencia procesal en el pais.

\section{La enserianza jusfillosófica}

La formación filosófica y humanista y el talento personal de Alzamora Valdez le permiten actuar, con calidad y hondura, en diversos campos del saber. Por ello, al superar los marcos de una determinada especialización, aborda con maestria materias aparentemente disimiles como la Ciencia Procesal, Ia Filosofia del Derecho o el Derecho Municipal.

Diversas promociones de estudiantes de San Marcos y de otras Universidades se han beneficiado con la lectura y reflexión del macizo pensamiento contenido en los tersos libros y ensayos que Alzamora Valdez ha dedicálo a la meditación jusfilosóficn. Al igual que lo acontecido tratándose del Derecho Procesal Civil, a partir de 1948 en que asume la respectiva cátedra. Alzamora renueva también la ensenanza del curso de Introducción a la Ciencia Juridica en nuestra cuatricentenaria Universidad, otorgandole a la materia dimensión filosofica. Su obra "Introducción a 
la Ciencia del Derecho" se convirtió, desde su publicación en 1963, en libro de obligada consulta para todos aquéllos, profesores, alumnos o abogados, que requieren de información seria, profunda y coherente sobre $\tan$ básica disciplina. Texto de indispensable lectura en esta área del saber jurídico, la obra de Alzamora Valdez ha merecido diez ediciones y fue justamente galardoneada en 1963 con el Premio de Fomento a la Cultura, oportunidad en la que tuve el privilegio de compartir dicho Premio con el maestro por mi obra "La noción jurídica de persona".

La valiosa producción jusfilosófica de Alzamora Valdez, centrada en el personalismo tomista, se hace patente primordialmente a través de las lecciones que imparte como profesor del curso de Filosofía del Derecho en la Sección Doctoral y luego en el ciclo profesional de la Facultad de Derecho de San Marcos, En 1973 publica su libro titulado "La Filosofia del Derecho", reeditado a la fecha.

El pensamiento jusfilosófico de Alzamora Valdez, que se nutre fundamentalmente del tomismo, ha estado siempre abierto al aporte de otros pensadores y escuelas, los que merecieron la seria y crítica atención del maestro, y cuyas ideas se recogen en sus obras. La honestidad e inquietud intelectual, así como la connatural capacidad de Alzamora Valdez hacen que se mantenga siempre informado $y$ al dia, lo que se evidencia en su producción intelectual. Este hecho se advierte, en especial, en su obra "La Filosofia del Derecho en el Perú" que, editada en 1968, se encuentra agotada por lo que se espera su pronta reedición dada su calidad y la importante contribución que tal libro significa para el cabal conocimiento de la evolución del pensamiento jusfilosófico en nuestro pais.

En todas las obras que precedentemente hemos resenado, y en ensayos publicados en diversas revistas, es dable aprehender el pensamiento medular de Alzamora Valdez en lo que a la jusfilosofia se refiere. Segán el maestro, la Filosofía del Derecho "no constituye una disciplina particular ni debe ser considerada como una rama o parte de la Filosofía, sino como la Filosofia misma en cuanto extiende su mirada hacia los ideales jurídicos y al modo como so han realizado a través de las diversas etapas de la historia" ${ }^{3}$. La Filosofía del Derecho, según el maestro Alzamora, pertenece a la pluralidad de disciplinas cuyo tema es el hombre $y$ se despliega a través de "la investigación de los principios superiores

3 "Lat Filosofí del Derecho en el Perá". Lima 1968, páz, 3. 
que inspiran la regulación de su conducta social hacia un modelo de vida" 4 . De lo expresado por el maestro sanmarquino se desprende que el campo propio de la investigación jusfilosófica, su tema principal, está constituido por los valores juridicos que "pertenecen al orden universal de los valores humanos" s. Lo expuesto hace que Alzamora Valdez concluya que surge clara la intima trabazón entre la Filosofía y la Filosofía del Derecho.

\section{La concepciön del Derecho}

El Derecho, según Alzamora Valdez, se sustenta en la libertad. El hombre, en cuanto persona, "es una unidad espiritual coherente y estable que se afirma frente a las otras personas y frente a las cosas, en tanto que libertad creadora de su propio destino" "6 . La persona, según el maestro, y en concordancia con el pensamiento existencialista, "no constituye algo fijo y acabado que se da de una vez y para siempre, sino un principio dinámico y creador que forja su propia historia" 7 . Por ser libre, y en tanto ente espiritual, el hombre "no se inserta en el enlace de causas y efectos que constituye el mundo físico" 8 . La persona, fuente creadora de su proyecto existencial, "vale como fin en sí misma, por lo cual jamás puede ser considerada como medio al servicio de otro fin, cualquiera que éste sea". En esta última expresión Alzamora Valdez resume la esencia del humanismo, posición en la que coinciden diversas corrientes de pensamiento de todos los tiempos.

De acuerdo con las ensenanzas del tomismo, y al recusar el pensamiento de ciertos autores de raigambre existencialista, Alzamora Valdez sostiene que "la existencia del hombre, que es historica por naturaleza, apoyada en su esencia, tiene como misión realizar su propio proyecto fundamental de vida ...". Es decir, "no es que el hombre sea sólo existencia que se hace a si misma, sino una creación libre que tiene como centro a lit persona que arraiga en su esencian" ${ }^{n}$. De este modo, al afirmar que ta esencia precede a la existencia, Alzamora Valdez descarta aquellas

\footnotetext{
4. "La Filosofia del Derecbo", I ima, 1976, pig. ?

5 "La Filosofía deI Derecho en el Perú", píg, 6

6 "La Fillosolia del Derecho", päe, 159.

7 Id päe. 162

8 Id pág. 163.

9 14. pue 160 .
} 
corrientes que, dentro del amplio cauce del existencialismo, dejan de lado la ontológica sustentación del hombre al prescindir de la esencia. Es este hombre, esta persona, la que resulta el centro del Derecho.

De todo to hasta aquí brevemente glosado del pensamiento jusfilosófico de Alzamora Valdez se deduce, como el propio maestro sefiala, que el Derecho pertenece al mundo de la cultura "constituido por las objetivaciones del espiritu humano que, a la vez que expresan valores, senalan un debe ser" 10 . En coincidencia con Recaséns Siches, el maestro señala que la Filosof ía del Derecho en "cuanto se trata de los valores objetivados en normas, como pensamientos pensados, y en si mismos, es Ontología, Lógica y Axiología del Derecho". "11

Son precisas y útiles las reflexiones que Alzamora Valdez dedica a las relaciones entre el hombre y la sociedad, en tanto que filosóficamente el ser humano existe con los demás seres humanos "y su existencia es inescindible de la existencia de los otros" 12 . En este orden de ideas, al evidenciar el imperativo de la sociedad para el hombre, el maestro rebate los argumentos del individualismo y del sociologismo, en tanto "representan dos extremos teóricos en la explicación de las relaciones entre el hombre y la sociedad". Alzamora Valdez destaca que de la necesidad de la sociedad para el hombre no se concluye que este último deba ser considerado como "un simple elemento de la misma o que deba ser absorbido por aquélla" ya que, citando a Venet, Alzamora Valdez estima que en la persona existe "una región profunda que es absolutamente impenetrable a la sociedad: la vida espiritual de la persona escapa a la sociedad y no puede ser determinada por ella" ${ }^{3}$. No obstante lo dicho. el maestro expresa que "en cuanto el individuo no puede prescindir de la sociedad en orden a la satisfacción cie su necesidad se halla subordinado a ésta; pero, si se tiene en cuenta que el hombre es persona -que es fin en si misma y jamás medio - con un destino espiritual que realizar, la socicdad se halla subordinada al hombren 19

Al reconocer que el Derecho pertenece al mundo de la cultura, el maestro sostiene que lo juridico significa la conjunción de tres elemen-

10 "La Finosofía del Derecho en el Perú", pág. 132

11 Id paic 132

12 Id. "La filosoría del Detecho", pis. 168.

13 14, páz: 174

14 lit, póf. 174 
tos: la vida, la normatividad y el valor, por lo que el Derecho podrfa definirse como "la regulación de la vida social del hombre para alcanzar la justicia" 15

Alzamora Valdez sintetiza lo que podría ser su visión personalista sobre el derecho, al afirmar que esta tendencia "proyecta la investigación hacia los dos fundamentos del derecho: la persona como ser espiritual, y los valores a través de los objetos específicamente jurídicos: las normas" ${ }^{16}$. En esta última expresión podriamos encontrar resumida la posición de Alzamora Valdez en lo atinente al Derecho, el mismo que no "constituye un poder físico sino un poder moral derivado de la vocación consustancial del hombre hacia su fin racional, se cjerce en la sociedad, frente a otros hombres" 17 .

En la concepción del Derecho que nos ofrece Alzamora Valdez, el fenomeno juridico "significa la conjunción de tres elementos: la vida, la normatividad y el valor ....". El rol del jurista aparece con delineados contornos e inequivoca función social. El jurista, en palabras del propio Alzamora, es el hombre que invoca la justicia y la realiza, "no se limita al estudio y análisis de la ley para aplicar la ley por la ley". Este simple mecánico ejercicio constituiria "traición a los fines de la inteligencia", ya que "el auténtico hombre de derecho -abogado, juez, consejerose vale de la norma como camino para alcanzar lo justo" is ,

\section{El bien común}

El hombre en su afán de perfeccionamiento, según Alzamora, tiende hacia el bien que, de acuerdo a Santo Tomás, es un fin. La perfección que apetecen los seres, siempre según las enseñanzas del Doctor Angélico, es una propiedad de todo ente para completar su inacabamiento ${ }^{19}$. El bien, si se tiene en cuenta la naturaleza coexistencial del hombre, es una tarea solidaria de los hombres en sociedad dirigida hacia el bien común. Este bien común se endereza hacia un doble propósito ya que tiene que

is "Introduestón a la Ciencia de1 Derecho", 5a, ed., Lima, 1972, picz. 28.

16 "La Filosofía del Derecho en el Perú", pás. 132, 17 "La Falosofia del Detecho en San Murcos: 1936-1976". Rev. Dereche y Ciencias Politicas,
Vol, 40, No, 1, 2 y 3, ene-die. 1976, paig, 205.

18 En palabra de agradecimiento en el hounenaje que le tributara el Calegio de Alogrados de Lima et 3 de Novierabre de 1982, Revists det Foro, Año LXIX, No. 2, Lims, Julio-Diciembere
1982 , paig. 212. 
ver con la perfección del todo social - del cual es causa - y con la de cada hombre en particular según los requerimientos de desenvolvimiento individual. El bien común, que es fin del Estado, significa según Santo Tomás "un orden justo", estable y seguro para la vida suficiente de una comunidad" ${ }^{20}$. Como anota Alzamora Valdez, el Doctor Angélico. siguiendo a Aristóteles, erige a la virtud como el centro mismo del bien común. ${ }^{21}$

El bien común, al cual el maestro Alzamora Valdez dedicará un próximo libro, ha tomado un nuevo sentido en los tiempos que corren bajo la denominación de "desarrollo", el mismo que, según la Encíclica "Populorum Progressio" de Paulo VI, no se reduce al mero crecimiento económico, sino que debe ser integral. Esto significa promover a todos los hombres $\mathrm{y}$ a todo el hombre, finalidad que no es posible alcanzar sin el desarrollo solidario de toda la humanidad ${ }^{22}$.

\section{El ser y el valor}

Alzamora Valdez, como demostración de su clara e intima compenetración con el pensamiento de Santo Tomás, que él domina, escribe en 1975 un excelente ensayo sobre "El ser y el valor en la filosofía de Santo Tomás", el mismo que es recogido en un volumen titulado "La aventura intelectual de Santo Tomás" ${ }^{23}$. En páginas esclarecedoras, lúcidas y limpidas, con rigor y concisión, Azzamora Valdez evidencia el extraordinario equilibrio con el que Santo Tomás "analizó la relación entre el valor y el ser a través de su doctrina de los trascendentales, que constituye la clave para la comprensión de la naturaleza del valor, de su conocimiento y de su realización" 24 . La lectura de este ensayo, en el que Alzamora Valdez nos muestra el grandioso sistema filosofico tomista, produce un verdadero placer intelectual.

Como bello epílogo del ensayo que comentamos, el autor expresa que la cultura consiste en la realización de valores "entendidos como inseparables cualidades del ser gue es su portador, gracias a la obra creadora

19 "La Fulosofia del Derecho", púb, 175

21 "El pensasiciento de Raúl Ferrero R.", Lima, 19?8, pág. 13.

22 TId, pág. 182

23 "La aventurs intelectual de Sasto Tounis", Lima 1975, pate 69 y ers,

24 id, pás. 72 
del espiritu humano y en orden a la elevación de la persona" que, en frase de Sunto Tomás, "es lo más noble de la creación" 25 ,

\section{El Derecha Municipal}

La versatilidad intelectual del maestro Alzamora, fundada en su poderoso intelecto y su capacidad filosófica, le permiten incursionar con originalidad y equilibrio en diversas materias. Claro ejemplo de ello son sus libros dedicados al "Derecho Municipal" y a "Los derechos humanos y su protección". En el primero de ellos, al sustentar la autonomía de la disciplina, el maestro sen̂ala que el municipio "representa una profunda exigencia para la persona humana, cada vcz más absorbida por la masa y cadla vez más dominada por poderes que atentan contra la libertad" 26 .

Al maestro Alzamora se debe la creación del curso de Derecho Municipal en la Universidad de San Marcos y la formulación, en 1962, de un excelente proyecto de Ley de Municipalidades. En este proyecto se delinea con nitidez la función del Alcalde, distinguiéndola de aquella otra de carácter deliberante, propia del Concejo. Lamentablemente, dicho proyecto no llegó a convertirse en ley no obstante lo cual influyó en el dispositivo legal que actualmente rige ta materia, el mismo que recogío algunos aspectos del articulado del proyecto.

El citado proyecto de Ley Municipal fue acompanado de otro complementario sobre Concejos Departamentales, el mismo que refleja el pensamiento de Alzamora Valdez sobre la ineludible necesidad de descentralizar el pais mediante la creación de organismos regionales.

\section{Los derechos humanos}

El libro sobre "Los derechos humanos y su protección" 27 es el fruto del quehacer y experiencia de Alzamora Valdez, entre 1968 y 1972 . como miembro de la Comisión Interamericana de Derechos Humanos de la Organización de Estados Americanos con sede en Washington. Como lo indica el autor en el pórtico de la obra, "la vigencia y el respeto

2510, ph 106.

26 "Derecho Muuicipal", Lima, 1972.

27 "Los Derechos Humanos y su protesción". Lima, 1937 
universal de los derechos humanos constituyen los problemas más graves de la sociedad de esta época", derechos que son negados tanto por la violencia institucionalizada como por la violencia revolucionaria "y con lo que se niega también la dignidad del hombre".

El libro de Alzamora Valdez cubre diversos aspectos de la rica y compleja problemática de los derechos humanos, El autor nos ofrece, con su acostumbrada claridad y hondura, una visión histórica de la evolución de tales derechos fundamentales, ensaya su sustentación filesofica y efectùa su análisis jurídico, incidiendo principalmente en los mecanismos de protección que fluyen tanto de los pactos y convenciones internacionales como de las legislaciones nacionales sobre la materia.

Es de sumo valor la glosa y el certero comentario crítico sue hace el autor de las diversas Declaraciones y Convenciones Internacionales de Derechos Humanos vigentes en el mundo actual. La obra es de excepcional utilidad para todo aquél que desee adentrarse en el estudio de tan delicada como apasionante materia de carácter multidisciplinario.

\section{Ensayos y articulos}

Son múltiples los ensayos y artículos escritos por Alzamora Valdez dispersos en revistas del Perú y del extranjero. Su comentada versatilidad facilitan el que se desplace por diversos campos del saber con soltura y solvencia intelectual.

No intentaremos, en esta ocasión, formular un elenco exhaustivo de tan vasta como rica producción cultural. Basta citar, a modo ilustrativo, los ensayos dedicados a rendir homenaje a figuras destacadas de la vida jurídica y política del país, como serian los casos, entre otros, de aquéllos referidos a José Luis Bustamante y Rivero, Raúl Ferrero, Germán Aparicio y Gómez Sánchez. Al lado de ellos podemos enumerar, siempre a guisa de ejemplo, los articulos concernientes a "El papel de la OEA en la protección de los derechos humanos". "Universidad y Estado". "El Consejo Nacional de Justicia", "La modernización del proceso civil en el Perú". "La Ensenanza del Derecho Procesal Civil en la Universidad Nacional Mayor de San Marcos; 1936-1976". "La Filosofia del Derecho en San Marcos: 1936-1976" y el "Derecho de rebelión", de reciente data. 


\section{El derecho de rebelión}

Cabe destacar que el ensayo atinente al derecho de rebelión constituye un versado trabajo sobre tan delicado tema. Con la seriedad y prolijidad que lo caracterizan, Alzamora Valdez analiza en dicho escrito aspectos inéditos de dicha figura en nuestro medio, lo que resulta de suma utilidad para el deslinde teórico de la materia. En el texto del mencionado ensayo el autor se refiere a las formas que asume la rebelión, o sea, a la oposición a las leyes injustas, la resistencia a la opresión y la revolución. El maestro sellala que cuando los que gobiernan incumplen el derecho y no realizan la tarea suprema del bien común, "los gobernados adquieren el derecho de rebelarse" 28 . En el mencionado ensayo el autor se ocupa también de otros asuntos de no menor interés, como son el estudio del derecho de resistencia a través de la historia, la problemática de la tirania y el tiranicidio y el amparo del derecho de rebelion en las Declaraciones de Derechos Humanos y en las Cartas Constitucionales.

Alzamora Valdez enumera los casos en que, segûn la doctrina de Santo Tomás, las leyes pueden ser injustas, o sea:

a) cuando el legislador ultrapasa su competencia,

b) cuando son contrarias a otras superiores;

c) cuando no buscan el bien común;

d) cuando no respetan la justicia distributiva; y

e) cuando imponen tareas incompatibles con la capacidad y los medios del sujeto.

La resistencia a la opresión "es la revuelta de los gobernados contra la violación por los gobernantes del derecho que deben respetar o cuando sobrepasan el poder que ejercen". La revolución, en cambio, persigue el establecimiento de un nuevo orden jurídico que supere "los defectos o los vacios del orden jurídico vigente en la conciencia de los pueblos" 29 .

En el artículo en referencin merecen especial mención los artículos 82 y 307 de la Constitución peruana, vigente desde 1980, en los que se establece, respectivamente, el derecho del pueblo de insurgir en defensa del orden constitucional y el hecho que la Constitución no perdera su vigencia si fuera derogada ilegalmente, prescribiéndose las sanciones

28 "Tl derecho đe rebelión" en Rev. "Defensa Nacional", del Centro de Altos Estudios Militures, ABo III, No. 3, Oot, 1983, Jfe. 37 y sgts.

29 Id, pás, 38. 
imputables a los responsables de la abrogación de la Constitución.

\section{La capacitación judicial}

No pueile omitirse entre las múltiples tareas académicas debidas a la fértil iniciativa del maestro Alzamora el haber creado el Programa o Escuela de Capacitación Judicial, del que es Director. La instalación de dicha Escuela responde a su convicción acerca de la misión esencial del Juez, que no es la de aplicar mecánicamente la ley, sino la de impartir justicia utilizando el intrumental normativo.

El comprender y enaltecer de este modo la excelsa y creadora función judicial lo llevan, en respuesta a una antigua y cardinal inquietud, a fundar tal Escuela destinada a la formación de hombres que no sólo deben conocer el ordenamiento legal vigente sino, básicamente, estar capacitados para, en expresión de Carlos Cossio, comprender conductas humanas en interferencia intersubjetiva, a fin de encontrar en ellas su sentido valioso ${ }^{30}$. El Juez debe ser un hombre especialmente dotado para sensibilizar la justicia en las relaciones humanas, como el artista es el ser predestinado a sensibilizar la belleza, el santo la virtud o el economista la utilidad.

La Escuela de Capacitación Judicial, que opera desde hace aproximadamente veinte años, está abierta a todos aquellos abogados que sientan vocación judicial, los mismos que son admitidos después de un examen de ingreso. Alzamora, al valorar la importancia que tiene para la vida juridica del paŕs la capacitación de jueces probos e idóneos, no ha economizado esfuerzos para mantener la Escuela en actividad, no obstante las innumeras dificultades que ha debido superar.

\section{La función püblica}

Alzamora Valdez es, por definición, un intelectual, un hombre dedicado a la noble y silenciosa tarea de pensar. Empero, como hemos podido apreciar del breve recuento de su actividad académica, tanto su vocación humanista como su disposición de servicio, unidas ambas a una desbordante incuictud por lo humano y a una extraordinaria capacidad creadora, lo llevaron, en mérito a sus altas y reconocidas calidades, a enaltecer y

30 Carlos Cossio, "U] derecho en el derecho judicial", Huenos Aines, 2a. ou. 1967 
desempeñar con éxito diversas actividades públicas, ef́vicas, politicas y gremiales. Sin dejar nunca de ser y comportarse como un intelectual, Alzamora Valdez fue elegido Decano diel Colegio de Abogados de Lima, parlamentario, diplomático y funcionario público de alto rango. Todas estas funciones fueron prestigiadas con su resencia, siempre brillante, y siempre dejó en ellas impresa la huella de su indiscutible talento creador. En todas ellas proyectó su vigorosa personalidad y su patente estatura moral.

Necesitaríamos, como es imaginable, numerosas páginas para dar cuenta de la vasta obra que realizó Alzamora Valdez en su polifacética actividad y quedarian aún muchas pendientes de escribir a la espera de la realización de sus futuros proyectos. No obstante que somos conscientes de esta limitación vebemos trazar, en gruesas pinceladas, las líneas maestras de las múltiples y disímiles funciones que ha cumplido en lo que va corrido de su fructifera existencia.

\section{La tarea cívica}

Mis recuerdos de Alzamora Valdez, nuestra antigua amistad y reciproco aprecio, se remontan a los anos en que era aún estudiante de Derecho, en la segunda mitad de la década de los años 40, época en la cual el maestro iniciábase en la docencia en la Facultad de Derecho de nuestra querida San Marcos, No tuve el privilegio de ser su alumno, pero ello no fue óbice para que su presencia en el claustro, las referencias de sus discipulos y la lectura de sus obras, hicieran nacer en mí una admiración y un respeto indeclinables hacia su persona y su obra. Nació asi una invariable amistad, sin sombras ni claroscuros, la misma que hoy por felicidad nos acompana. Por ello, como colega y amigo, puedo dar personal testimonio de sus altas calidades humanas c intelectuales, de su envergadura moral y singular talento.

Evoco a Alzamora Valdez como compañero mayor en la primera e inolvidable aventura civica de mi vida, en la que apoyamos, con desinterés $y$ sin regateos, el insurgir de un movimiento político de amplia base, que pudo ser el inicio en el Perú de una nueva era democrática, bajo la límpida conducción de ese patricio que es el doctor José Luis Bustamante y Rivero, experiencia truncada casi al nacer por el golpe aleve de las fuerzas de las tinieblas.

Algún tiempo đéspués nos reencontramos, en la década de los años 50. hermanados por la común tarea cívica de luchar contra un dañino 
autoritarismo político. Puedo dar fe de su permanente afán de servicio cuando en 1956 fue elegido parlamentario.

\section{La labor parlamentaria}

Entre 1956 y 1962 el maestro Alzamora, representando a Cujamarca. ocupó un escaño en la Cámara de Diputados. Su paso por el Congreso estuvo signado por un trabajo tenaz, por un renovado empeño por dignificar la función parlamentaria. Sus intervenciones fueron siempre oportunas, brillantes y precisas. De su fecunda imaginación y experiencia brotaron numerosos proyectos de ley. Aparte del proyecto de Ley de Municipalidades, al cual nos hemos referido anteriormente, bastaría recordar al efecto los proyectos de Ley de Bases Universitaria, que culminó con la ley 13417, del pasaje universitario, de rentas para la Universidad, de Archivos Nacionales, de Unjversidades Técnicas, de profesionalización de los contadores públicos, de aranceles juridicales, del Consejo Nacional de Educación, de Ley de Bases de la Educación Nacional, de renovación periódica de los miembros de la Corte Suprema, para mencionar algunos de ellos. Varios de tales proyectos se convirtieron en leyes, otros sirvieron de inspiración o modelo de otros proyectos o leyes, algunos esperan aún la coyuntura propicia para ser desempolvados de los archivos del tiempo.

\section{El Colegio de Abogados}

Alzamora Valdez, a fines de 1965, accede, sin competidores, al Decanato del Colegio de Abogados de Lima. Su capacidad, su experiencia y su dinamismo, su probada vocación de servicio, dieron lustre a la función y hoy se rememora su tránsito por dicho Decanato como uno de los más fecundos que reconoce la historia de dicho Colegio. Desde tan honroso sitial el maestro continuó dictando cátecira, irradiando su devoción por la Orden de los Abogados. Varias son las realizaciones en su haber, producto de su preocupación por dignificar el noble ejercicio de la profesión de abogado. Cabe citar, entre otras, la Tabla de Honorarios Mínimos, la publicación de un Bocltin Mensual, la organización de Congresos ae Decanos de Colegios de Abogados, el insistente reclamo por la creación de un Consejo Nacional de Justicia, la dación de un Código de Etica Profesional, la modificación de los estatutos del Colegio, el funcionamiento de Consultorios Jurídicos Gratuitos en los Pueblos Jóvenes, el acuerdo para examinar, con eriterio juridico-científico, las ejecutorias judiciales, la instalación de la Academia Penuana de Derecno 
El Decanato sirve a Alzamora Valdez para "con terco e indssmayable empeño". continuar la honrosa tradición del Colegio de Abogados de Lima en defensa del Derecho Como el propio maestro lo señala, el Colegio se erigió a través de su historia en "uno de los paladines más calificados de la rectitud cívica" y se constituyó en sustentador de la validez y vigencia de la ley justa, en "incesante buscador de la probidad y de la buena fe en el reconocimiento de la dacion de lo suyo a cada cual" y en dispensador de ayuda y apoyo de sus miembros y, sobre toco, "en promotor de valores éticos como bases de una sociedad ordenada democráticamente" 3

Alzamora Valdez, al insertarse en esta noble tradición, ajusta permanentemente su incansable accionar ejecutivo en esta valiosa dirección.

Corresponde a Alzamora Valdez la feliz iniciativa de crear ba Fedienación de Colegios de Abogados, de la cual fue su primer Vice-Presidente. Como resultado de las elecciones efectuadas en el Congreso de Abogados del Cusco, fue ungido en 1968, como Presidente de dicha naciente Federación.

\section{El educador}

Educador por antonomasia, Alzamora Valdez ha estado siempre vivamente interesado por los asuntos vinculados con la formación de fa juventud. No fue casual, por tanto, su activa participacion como Presidente de la Comisión que formuló el Proyecto de Ley de la Educación Secundaria en 1952, ni el rol de primer onden que le cupo como Presidente de aquella otra Comisión que preparó el Proyecto de Ley de Bases Universitaria, que culminó con la dación de la recordada ley 13417 que. al decir de muchos, fue la mejor que ha conocido nuestro país. Tal como oportumamente lo anotáramos, el maestro Alzamora, tenaz e incansable al impulso de tan noble vocación, proyectó como parlamentario sendos proyectos de ley sobre el Consejo Nacional de Educación y de Bases de la Eutucación Nacional.

El aporte de Alzamora Valdez a la educación nacional trasciende su propia actividad docente y labor legislativa, para complementarse con la edición en 1961 del libro titulado "La educación peruana: crisis y

31 En pubtras de apradecimieoto al homemaje tributaito pos el Cotepio de Abogadios de Limat. 
perspectiva". obra en la que se recogen sustanciales enfoques sobre tan importante materia que permanentemente atrajo el interés y el serio tratamiento del autor.

\section{Los Congresos de Facultades de Derecho}

El nombre de Alzamora Valdez está intimamente ligado no solo a la investigación y la docencia en nuestra Patria, sino que su constante inquietud y su persistente afán de ser útil lo hacen estar presente en los Congresos de Facultades y Escuelas de Derecho celebrados en América Latina. En cada uno de ellos fue protagonista de primera línea.

Fue gestor de numerosas iniciativas para mejorar el nivel de la ensenanza juridica en las Universidades de esta parte marginal del mundo y elaboró sesudas ponencias y atinadas mociones que fueron cálidamente acogidas en dichos foros interuniversitarios. Especial mención merece el meditado Plan de Estudios para las Facultades de Derecho de América Latina que fucra presentado por Alzamora Valdez y aprobado por el Congreso celebrado en Lima.

Alzamora participó en las reuniones habidas en México, Lima, Santiago de Chile y Córdoba e hizo llegar una ponencia a la reunión de Bogotá. En alguna de ellas fue honrado como ponente oficial o Presidente de Asamblea. Recuerdo personalmente el brillo que acompanó todas las intervenciones del maestro en los Congresos de Santiago de Chile y Córdoba, en los que me tocó intervenir en representación de la Facultad de Derecho de la Universidad de San Marcos.

\section{El diplomático}

Infatigable macstro, intelectual rico en imaginación e ideas, Alzamora Valdez dejó siempre huella notable de su paso en cuanta actividad le cupo desempenar. Cuando fue Embajador en Francia, no solo representó con lustre al pais en todo aquello propio de tan delicada gestión, sino que se dio tiempo para participar en la vida cultural de esa nación y editar un folleto titulado Visión del Perú, cuya divulgación permitió un mejor conocimiento de nuestra Patria y un eficaz estimulo para el turismo receptivo ${ }^{32}$. 


\begin{abstract}
En esta misma época asumió la representación del Perú ante la UNESCO.
\end{abstract}

\title{
24. La Asociación Juridica Peruana
}

En 1977. en plena crisis de la vida universitaria, en instantes en que cundía el desaliento por la infecundidad del trabajo científico-juridico en el jais, un grupo de profesores de San Marcos decidió fundar un centro de investigación y divulgación del Derecho que supliera parcial y momentaneamente las carencias advertidas. En esta empresa, que nos cupo organizar, contamos con la presencia de maestros de la talla de José León Barandiarán, José Pareja y Paz Soldán, Francisco Miró Quesada Cantuarias, El anaestro Alzamora aparece como Vice-Presidente $y$ animador de la naciente Asociación Juridica Peruana.

Por aquel entonces tal entidad, a través de diversos ciclos de conferencias, presentó a un numeroso público, ávido de conocimientos, las más recientes tendencias del derecho comparado contemporáneo y los lineimientos básicos que deberian servir para la necesaria claboración de una nueva Constitución de la Republica.

La Asociación Juridica Peruana, en la que sin duda han de congregarse profesores de otras promociones, trazó proyectos de investigación y diocencia juridica a alto nivel que no han perdido vigencia $y$ que pueden, en cualquier momento, tener cabal cumplimiento.

\section{El Profesor Emćrito}

El breve y parcial bosquejo de la rica y polifacética actividad y obra de Mario Alzamora Valdez, que hemos realizado en estas páginas, lo muestran como un auténtico maestro que durante más de cuarenta años brindó su invalorable aporte al pais y a la Universidad Peruana. Su presencia cuibre $y$ otorga prestancia a toda una reciente etapa de la historia de la Facultad de Derecho de San Marcos. De ahi que pocas reces sea más justificado y merecido el homenaje yue en esta noche memorable le rinde la Universialad de San Marcos al incorporarlo como Profesor Emérito.

Mís alla de coincidencias o discrepancias que se pueda tener con determinadas concepciones del maestro Alzamora Valdez, es Gable perci- 
bir el unánime reconocimiento de la comunidad nacional a su senera obra intelectual. Es mucho to que el maestro, a través de los anos, nos ha entregado generosamente, pero es mucho también lo q̨ue se espera aủn de su inagotable talento creador.

En Alzanora Valdez identificamos al hombre preocupado, pero siempre esperanzado, que alguna vez expresó que "entre nosotros el pleno y sincero reconocimiento de la dignidad humana, abrirá el camino hacia esa urgente revolución de la igualdad contra los privilegios del poder $y$ del dinero, que se han consustanciado en instituciones y costumbres, y que represcntan la más dolorosa negación del orden jurídico y han trastocado la Ley en una estructura ficticia, la justicia en un mito para incrédulos y la democracia en una organización teórica y fałaz" 33 .

Resuenan aún en nuestros oidos las expresiones que pronunciara d maestro al agradecer el homenaje que en 1982 le rindiera el Colegio de Abogados de Lima y que podrían resumir su proyecto vital: "somos luchadores sempiternos; combatimos indesmayables; rebeldes con una causa, un mundo mejor, protagonistas de todos los cambios en pro de las eternas aspiraciones del hombre".

Arrogândonos, inmerecidamente, la representación de la comunidad sanmaxquina cumplimos con el privilegio de expresar, sencilla pero sentidamente, junto con nuestra gratitud al maestro Mario Alzamora Valdez, la fundada esperanzal de seguir enriqueciéndonos en el futuro con las luces de su sabiduria humanista.

33 Discurso promunciado el 15 de enero de 1968 in th homenaje del Colegio de Abogados de Lima al Di. José Lats Bustamante $y$ Rivero




Bibliografía del Doctor Mario Alzamora Valdez

\section{Libros}

I. Marxismo Fülosófico. Lima, 1934.

2. Metafísica. Ed, Lumen 1937, Lima.

3. Psicologia. Ed Lumen 1938, Lima.

4. Derecho Procesal Citul. Teoria General del Proceso. Editorial Lumen 1953. (Ha alcanzado ocho ediciones)

5. La educación penana: crisis y perspectiva. Ed. Universitaria, Lima, -at 1961.

6. Introducciön a la Ciencia del Derecho. Gráfica P. L. Villanueva S.A. 2b) Lima, 1963 (Nueve ediciones).

7. Derecho Procesal Civil, Teoria del Proceso Ordinario, Lima, 1966 Sonoi(Dos ediciones).

8. La Filosofúa del Derecho en el Perú. Librería Editorial Minerva, TrelLima, 1968.

9.

10. Derecho Municipal. Ed. Rávago, Lima, 1972.

11. Filosofia del Derecho. Editorial Sesator, Lima, 1976.

12. Los Derechos Humanos y su protección. Jus, Lima, 1977.

Con otros autores:

13. La aventura intelectual de Santo Tomás. Grúfica P.L. Villanueva, Lima, 1975.

14. Legislación del abogado. (Dos ediciones) Colegio de Abogados de Lima, 1966 y 1967.

15. La nueva Constitución y su aplicación legal F. Campodónico, Editor, Lima, 1980. nixineore

\section{Folletos}

1. La Tercera Conferencia General de la Asociación Internacional de Universidades. Universidad Nacional Mayor de San Marcos. Lima, 1961.

2. Anteproyecto de ley de municipalidades y concejos departamentales. Pacific Press, Lima. 1962 
3. La Abogaciá. Tres Conferencias sobre el Hombre de Derecho. Imprenta de la Universidad Nacional Mayor de San Marcos, 1963.

4. El vecino y la vida local. Bases para una legislación municipal, Editorial Universitaria, 1966.

5. La Constitución del Perú. Ed, Universitaria, Lima, 1967.

6. Homenaje al Doctor José Luis Bustamante y Rivero, Presidente de la Corte Internacional de Justicia de La Haya, Lima, 1968.

7. La Declaración Americana de los Derechos y Deberes del Hombre y los Organismos Internacionales. Imprenta de la Universidad Nacional Mayor de San Marcos. Lima, 1968.

8. Vision du Pérou. París, 1971 (100,000 folletos).

9. El Consejo Nacional de justicia ante la legislación comparada. Imprenta de la Universidad Nacional Mayor de San Marcos. Lima, 1973.

10. La modernización del derecho procesal civil en el Peri. Revista de Derecho y Ciencias Politicas, marzo-dic. 1975.

11. La enseñanza del Derecho Procesal Civil en la Universidad Nacional Mayor de San Marcos de 1936-1976. Id. 1975.

12. La nueva Constitución. Talleres Gráficos J. Marín, Lima, 1977.

13. La Filosofía del Derecho. Revista de Derecho y Ciencias Políticas de la Universidad Nacional Mayor de San Marcos 1977.

14. El pensamiento de Raúl Ferrero. Lima, s/e, 1978.

Artículos sobre temas de Derccho, Filosofía, Muricipalidades y Educación

1. El significado de la Fenomenología. Revista de la Universidad Católica del Perí, 1933.

2. Filosofia de los valores. Id. 1935.

3. Principios de Metafisica. Id. 1936.

4. Descartes y el problema de la sustancia. Id. 1937.

5. Para una filosofía de la cultura. Id. 1939.

6. Cultura y Peruanidad. Anales del Segundo Congreso Iberoamericano de Estudiantes Católicos. 1939.

7. Bergson y el renacimiento de la sabiduria, Mercurio Peruano, 1941.

8. La Filosofía de Bergson. Revista de ta Universidad Católica, 1941.

9. Descartes y el pensamiento modemo. Id. 1942.

10. La cultura y la vivencia de fa tierra. Mercurio Peruano, 1942.

11. Concepción Racista del Mando, Revista de la Universidad Católica. Lima, 1943.

12. Reflexiones sobre el problena de la Filosofía. Revista de la Universidad Católica, 1944 . 
13. La caracterología. Revista Policial del Perú, 1944.

14. Ontologia del conocer. Archivos de la Sociedad Peruana de Filosofía, 1944.

15. Repartición y Desarrollo de la Inteligencia. Id. 1945.

16. El Problema de la Filosofía Cristiana. Revista de la Universidad Católica, 1945.

17. Derechos de la administración para modificar los contratos de concesión de servicios en el curso de su ejecución. Boletín del Ministerio de Gobierno, 1946.

18. Filosofía Existencial y Filosofia Cristiana. Archivos de la Sociedad Peruana de Filosofía, 1950.

19. El pensamiento de Bartolomé Herrera. Mercurio Peruano, 1950. (Hay separata).

20. La verdad en el proceso civil. Jurisprudencia Argentina, Buenos Aires, 5 noviembre 1952.

21. La verdad en el proceso civil. Mercurio Peruano, 1952.

22. La profesión de abogado. Revista del Foro, órgano del Colegio de Abogados de Lima, 1952.

23. La profesión de abogado. Revista Jurídica Dominicana. Ciudad Trujillo, República Dominicana, 1952.

24. El pensamiento jusfilosófico de Giongio Del Vecchio. Id. 1953.

25. La posibilidad de un no-derecho, 1d. 1953

26. El pensamiento de Riva Agüero. Mercurio Peruano, 1954.

27. Educación y concepción del universo. "El Comercio", 11 abril 1954.

28. El pensamiento áe Riva Agüero. (Folleto) Instituto Riva Agüero, 1955.

29. La mujer peruana ante el derecho. Mercurio Peruano, 1955.

30. Congreso de Abogados. Revista del Foro. Lima, 1955.

31. Homenaje a Eduardo J. Couture. Revista de Derecho y Ciencias Políticas, 1956.

32. El pensamiento de Bartolomé Herrera. "El Comercio", 20 junio 1956.

33. Ciudades del Perú: Cajamarca. "Mar del Sur", 1957.

34. La personalidad del Doctor Germán Aparicio y Gómez Sánchez. Revista del Foro, 1958.

35. Ineficacia del poder legislativo. Facecale. Lima, 2 diciembre 1958.

36. Universidad Técnica y Desarrollo Económico. "La Prensa", 10 octubre 1959.

37. La Segunda Conferencia de Facultades de Derecho Latinoamericanas. Revista de Derecho y Ciencias Políticas, 1961.

38. El pensamiento político de Bartolomé Herrera. Revista Militar del Perú. Lima, mayo-junio 1961. 
39. Los fundamentos doctrinales del Código de Procedimientos Civiles. Revista de Derecho y Ciencias Politicas, 1962.

40. A mensagem de Couture, Jornao do Foro. Lisboa, Portugal, 1962.

41. Los fundamentos doctrinarios del Código de Procedimietos Cúviles. Revista de Jurisprudencia Peruana, julio de 1962.

42. Los fundamentos doctrinarios del Código de Procedimientos Civiles. Revista de Jurisprudencia Peruana. Lima, julio 1962.

43. El jurista en el mundo de hoy. Revista del Foro, Colegio de Abogados de Lima, abril de 1962.

44. La ideologia de las constituciones pernanas de la primera mitad del siglo XIX. Cultura Peruana Lima, 1962.

45. La enserianza del Derecho y las Ciencias Sociales en los diversos grados de la educación. Revista del Ministerio de Justicia, Caracas, República de Venezuela. Enero, febrero, marzo 1962.

46. Bases para una política educacional. Revista Peruana de Cultura, 1962.

47. La nueva Ley Orgánica del Poder Judicual. Id. 1963 (hay separata).

48. La Constitución de 1933 a los 30 años de su promulgación. Id, 1963.

49. El pensamiento de Riva Agüero. Cuadernos Hispanoamericanos, Madrid, Espana 1963.

50. La nueva Ley Orgánica del Poder Judicial. Revista de Derecho y Ciencias Politicas, 1963. (Hay folleto aparte).

51. El Colegio de Abogados de Lima, Revista del Foro. Lima, 1963.

52. Posibilidad de incorporar el despacho saneador dentro del procedimiento civil peruano. Revista de Derecho y Jurisprudencia. Junio 1963, Lima.

53. La celeridad y aralidad en el proceso civil. Id. 1964.

54. Los tres momentos de la democracia. Revista del Centro de Instrucción Militar del Perú, Abril-junio 1964.

55. Los derechos de libertad e igualdad y los derechos sociales en las constituciones americanas. Boletin del Instituto de Derecho Comparado. Lima, 1964.

56. Municipalidades: una legislación anacrónica y varios intentos de reforma. "Expreso", 4 junio 1964.

57. Una organización funcional. "Expreso", 7 junio 1964.

58. Municipio y servicios públiceos. "Expreso, 15 junio 1964.

59. Los modos de gestión municipal. "Expreso", 21 de junio 1964.

60. La economia municipal. "Expreso, 27 junio 1964.

61. El Instituto de Administración Local de Madrid, Los centros destinados a la formación de jueces, Id. 1965.

62. Las muevas orientaciones del Derecho Procesal en las Nuevas Orien- 
taciones del Derecho. Colegio de Abogados de Lima, 1965.

63. La doctrina de la soberanía de la inteligencia según Bartolomé Herrera, Foro Chalaco. Callao, 1965.

64. Los derechos de libertad e igualdad y los derechos sociales en las constituciones anericanas. Boletín del Instituto de Derecho Comparado. Quito, Eeuador, 1965.

65. La justicia en la obra de Dante. Mercurio Peruano. Nov.-dic. 1965.

66. El problema de la universidad, Revista "Oiga", 23 julio 1965.

67. Munticipalización de los servicios públicos. "El Comercio", 11 julio 1965.

68. El Instituto de Estudios de Administración Local de Madrid. "E1 Comercio", 18 junio 1965.

69. Racionalización de la función municipal. "Ultimas Noticias", Caracas, Venezuela, 16 noviembre 1966.

70. La creación del municipio. Chiclayo, 29 agosto 1967. (Revista).

71. La abogacía como profesión, "La Voz Rotaria", 6 abril 1967.

72. Las vice-presidencias en el proceso constitucional. "Expreso", 3 abril 1967.

73. Los derechos humanos. "La Voz Rotaria". Lima, 22 diciembre 1967.

74. Proyecto de ley municipal. "Extra", 1967.

75. La desconcentración y la descentralización administrativas como conceptos de derecho administrativo. Conferencia en el Seminario de la Oficina Nacional de Racionalización de la Administración Pública. Lima, 11 diciembre 1967.

76. Bases juridicas de la verdad en el proceso. Revista del Foro, eneromarzo 1967.

77. La Organización del Tribuanal Supremo en diversos paises. Revistia del Foro, Abril-junio 1967.

78. La Academia Peruana de Derecho. Revista del Foro. Julio-diciembre 1967.

79. Los derechos humanos. Revista del Foro, enero-mayo 1968.

80. La nueva ley de Universidades. Gaceta Sanmarquina, 1969.

81. La universidad al servicio del desarrollo, "Correo", 25 noviembre 1969.

82. El voto del analfabeto. Revista "Mérito", octubre 1969.

83. La Universidad. "El Comercio", 16 marzo 1969.

84. La protección de los derechos humanos en el sistema interamericano. Revista de Derecho y Ciencias Politicas. Lima, 1970.

85. La arganización de los estudios de derecho en Francia. Revista del Foro, Lima, junio 1971.

86. Los fuidamentos epistemológicos de la Teoria Pura del Derecho. Revista de Derecho y Ciencias Politicas. Lima, 1972. 
87. El Municipio. "Ultima Hora", 9 agosto 1972.

88. Derecho Municipal. "El Comercio", 20 setiembre 1972.

89. La ley muricipal es el primer paso para alcanzar la vida democrática en el Perú. "El Comercio", 28 setiembre 1972.

90. Los alcaldes deben ser rentados. "Correo", 28 setiembre 1972.

91. El Consejo Nacional de Justicia, "Derecho", Pontificia Universidad Católica, Lima 1972.

92. Coordinación Interdisciplinaria. Universidad Nacional de Córdoba (Argentina). Edición Udual, México, 1973.

93. La certeza del derecho. "El Comercio". Lima, 1973.

94. El Derecho y la naturalezn de las cosas. "Derecho". Pontificia Universidad Católica. Lima, 1973.

95. El papel de la OEA en la protección de los derechos humanos. Revista de Ciencias Sociales, Universidad de Chile. Valparaiso, Chile, 1974 (existe separati).

96. Estructuralismo y derecho. "Derecho". Universidad Católica, agosto 1974 .

97. La Carte Suprema de Justicia en el sesquicentenario de su institución. Lima, 1975.

98. Coordinación interdisciplinaria, Enseñanza del Derecho y sociedad en Latinoamérica. Facultad de Derecho y Ciencias Sociales de la Universidad de Córdoba, Argentina-México 1975.

99. El municipio debe ser de participación plena. "Correo", 2 febrero 1975.

100. El papel del jurista y su interrelación con otras profesiones. Bogotá, Colombia, 1976 (UDUAL).

101. Las nuevas orientaciones del proceso civil. Cuadernos Agrarios. Instituto Peruano de Derecho Agrario. 1977.

102. La reforma del Código de Procedimientos Civiles en el Decreto Ley 21773. Revista de Jurisprudencia Peruana. Lima, marzo 1977.

103. El Doctor Raúl Ferrero. Revista de la Academia Diplomática del Perú. Enero-junio 1977.

104. La acción. Biblioteca de cultura peruana contemporánea. Ediciones "El Sol". Lima, 1977.

105. La Revolución de la Igualdad. "Correo". Lima, 15 noviembre 1977.

106. La historia del hombre es una lucha permanente por la conquista de sus derechos. Boletín de las Naciones Unidas, 7 diciembre 1977.

107. Los Derechos Humanos, Revista "Gente", 31 agosto 1977.

108. Los Derechas Humanos. Diario "La Prensa". Lima, 2 octubre 1977.

109. La autonomia municipal, "El Comercio". 13 junio 1977

110. La autonomía es un elemento histórico de las municipalidades. Revista Callao, 15 junio y 15 julio 1977. 
111. La expresión constitucional de la igualdad y de los derchos sociales. Revista del Foro, julio-set. 1977.

112. El Doctor Raúl Ferrero.-Economía y Finanzas. Revista de la Academia Nacional de Ciencias Económicas. Lima, 1978.

113. La eliminación del analfabetismo. "El Comercio", 8 noviembre 1978.

114. Homenaje a Luis Recasens Siches. "El Comercio". Lima, 21 enero 1978.

115. Los valores y los principios rectores de la Constitución. Revista "Gerencia", marzo 1978.

116. Los principios rectores de la Constitución. Revista Callao, abrilmayo 1978.

117. Derechos $y$ deberes fundamentales del hombre. Revista del Foro, Lima, 1979.

118. Educación y justicia. Segunda Conferencia Latinoamericana de Ejecutivos. Clade II. IPAE. Lima, 1979.

119. La violencia y sus formas. Revista Tiempo y Vida, 1980.

120. La Filosofia de Mariano Ibérico. Boletín de la Universidad de Cajamarca, 1981.

121. La Investigación Científica, Universidad Femenina. Lima, 1981.

122. Reglamento del recurso de casación. "El Comercio", 16 noviembre de 1981.

123. Francisco García Calderón Hombre de Derecho, Revista del Foro, 1981.

124. Proyecto de Código Civil. Su actual revisión debe ser sometida a debate nacional. "El Comercio", 26 noviembre 1982.

125, El pensamiento filosófico de Víctor Andrés Belaunde. Universidad del Pacífico. Lima, 17 de noviembre de 1983.

126. Homenaje al Secretario General de las Naciones Unidas Dr. Javier Pérez de Cuellar. "El Peruano", 27 abril 1984, Lima.

127. La enserianza del Derecho y las Ciencias Políticas en los diversos niveles de la educación. Revista de Derecho y Ciencias Políticas.

128. Seminarios de Derecho y Ciencias Sociales. Id.

129. Materias básicas en los planes de estudios de las Facultades de Derecho y Ciencias Sociales. Id.

130. La Constitución de 1933 a los 30 años de su promulgación. Lima, 1963. 